\title{
Sperm populations in the female genital tract of the rabbit
}

\author{
J. Cohen and K. R. Tyler \\ Department of Zoology and Comparative Physiology, and Department of Physiology, \\ University of Birmingham, P.O. Box 363, Birmingham B15 2TT, U.K.
}

\begin{abstract}
Summary. Spermatozoa were recovered from the uteri and oviducts of mated does between 0 and $14 \mathrm{~h}$ post coitum (p.c.). The proportion of spermatozoa binding IgG before and after treatment with normal rabbit serum was assessed by immunofluorescence microscopy. Most spermatozoa recovered from the oviduct and from the uterus $<3 \mathrm{~h}$ p.c. did not bind $\mathrm{IgG}$, in contrast to those of the ejaculate which did, and those from the uterus $4-10 \mathrm{~h}$ p.c. which were already coated with IgG when recovered. Spermatozoa transferred at $2 \mathrm{~h}$ p.c. to a recipient doe did not bind $\operatorname{IgG~} 4 \mathrm{~h}$ later, although a $6 \mathrm{~h}$ sample of the donor's spermatozoa did do so; only $\sim 150$ of these spermatozoa were needed for all fertilized eggs/doe, whereas $10^{4}-10^{5}$ ejaculated spermatozoa were required when similarly inseminated. We suggest that the small numbers of spermatozoa that do not coat with IgG and are first through the cervix are those which normally fertilize. Whether they are a separate population in the ejaculate is uncertain.
\end{abstract}

\section{Introduction}

The distribution of sperm numbers in the female tract after copulation by rabbits has been worked out by Braden (1953), Morton (1970), Overstreet, Cooper \& Katz (1978), and Overstreet \& Cooper (1978). About $200 \times 10^{6}$ spermatozoa are usually ejaculated into the vagina but only about $2 \times 10^{6}$ are found in the uterus and only a few hundred reach the site of fertilization in the oviduct.

Immunoglobulins of fertile female mammals have been found to coat the acrosomes of normal ejaculated spermatozoa (Edwards, 1969; Cohen, 1971), probably via the Fc end of the molecule (Cohen, 1978; Allen \& Bourne, 1978). Chang (1947) described the deleterious effect of fresh, but not heat-inactivated, serum on rabbit spermatozoa and Bedford (1969) described pathological changes associated with this effect. Several authors agree that IgG is probably responsible (Symons, 1967; Padma, 1972; Allen \& Bourne, 1978). Cohen \& Werrett (1975), using homologous sera from fertile animals to coat spermatozoa, described two populations of spermatozoa, only one of which bound immunoglobulin; they suggested that the majority, which bound $\operatorname{IgG}$, were progressively impeded and phagocytosed, leaving the non-coating minority to fertilize. Johnson \& Hunter (1972), using alloantibodies raised to rabbit sperm or surface coat antigens, showed that changes in binding occurred in the period between copulation and fertilization; only $10 \%$ of early uterine spermatozoa showed sperm surface antigenicity, compared with $90 \%$ of late oviductal spermatozoa.

Tyler (1977) showed that normal rabbit spermatozoa, but not seminal plasma to any great extent, caused a massive invasion of heterophils into the cervical epithelium of rabbit does within $30 \mathrm{~min}$ of insemination or mating; this inflammatory response seems part of the normal 
interaction between spermatozoa and the tissues and fluids of the female tract. Moreover, the first few spermatozoa recovered from the uterus, like oviductal spermatozoa, did not bind IgG from normal serum.

Cohen \& MacNaughton (1974) and Overstreet \& Katz (1977), using different experimental systems, provided evidence from re-insemination of oviductal spermatozoa that rabbit spermatozoa that have once attained the fertilization site are very much more likely to fertilize eggs than are competing ejaculated capacitated spermatozoa. Both experimental systems are open to criticism, however, and sperm sub-populations of different fertilizability have not yet been demonstrated unequivocally. Equivalence of such presumed populations with spermatozoa which differ in IgG binding (Cohen \& Werrett, 1975) has not been experimentally investigated.

In the present study, we have assessed the fertility and the IgG-binding of identifiable sperm populations.

\section{Materials and Methods}

\section{Sperm recoveries}

Eleven New Zealand White parous does were mated once to a buck of known fertility; after various intervals they were killed by an overdose of pentobarbitone sodium. The uterine horns and oviducts were separated by clamps and flushed by the procedure described by Cohen \& Werrett (1975), using $0.5 \mathrm{ml}$ warm phosphate-buffered saline (PBS, g/l: $\mathrm{NaCl}, 8 ; \mathrm{KCl}, 0.2$; $\left.\mathrm{Na}_{2} \mathrm{HPO}_{4} \cdot 12 \mathrm{H}_{2} \mathrm{O}, 2 \cdot 9 ; \mathrm{KH}_{2} \mathrm{PO}_{4}, 0.2\right)$ per oviduct, and $1 \mathrm{ml}$ of the same medium per uterine horn.

Samples $(20 \mu \mathrm{l})$ of each flush were taken for counting, using the fixed-drop method described by Cohen (1971), after suitable dilution with PBS, fixed in acetic-alcohol and stained with methyl blue-eosin B (Casarett, 1953). The remainder of the sample was prepared for immunofluorescence examination.

Small drops (approximately $5 \mu \mathrm{l}$ ) of each suspension were air-dried on chemically clean glass slides selected for low auto-fluorescence and marked to demarcate 10 areas on each slide. Each slide eventually contained small areas of spermatozoa from an ejaculate washed once (area 1) or 6 times (area 2) by repeated suspension in $10 \mathrm{ml}$ changes of PBS and centrifugation $(500 \mathrm{~g}, 5$ min); from uteri of 2 does sampled at different times p.c., washed once or 6 times (areas 3, 4, 5 and 6); from the oviducts of the same does (areas 7 and 8); and diluted rabbit serum (area 9) and washed rabbit tissues (area 10) as controls for the various stages of the staining procedures. Each slide was thus arranged to contain at least one sample of spermatozoa that were expected to stain negative, some expected to stain positive, and control spots. When all spots had dried, slides were fixed in dry acetone at $-20^{\circ} \mathrm{C}$ for $30 \mathrm{~min}$, and rinsed extensively in PBS to remove the acetone before staining.

Immunofluorescence staining was carried out using a procedure similar to that used by Cohen \& Werrett (1975). Serum from fertile female rabbits was used undiluted to test the fixed spermatozoa on the slides. Sheep anti-rabbit IgG (Behringwerke) was used to localize rabbit IgG on the spermatozoa, and rabbit anti-sheep IgG, fluorescein-labelled (Behringwerke), was used to visualize attached antibody. Generally, a red phase-contrast trans-illumination was used simultaneously with the blue exciting epi-illumination for fluorescein conjugates to provide simple and accurate sperm localization, especially of unstained spermatozoa.

\section{Sperm transfers}

Oestrous does of proven fertility were paired such that one was mated (once only) and the other was injected with 50 i.u. hCG at the same time. After $2 \mathrm{~h}$ each doe was anaesthetized with halothane (Fluothane: ICI) in oxygen and, at laparotomy, spermatozoa were washed from the 
uterus of the mated (donor) doe by flushing both uterine horns with $2 \mathrm{ml}$ warm PBS. These flushings were then injected into the uterus of the other (recipient) doe after removal of $150 \mu$ for sperm counts $(3 \times 20 \mu \mathrm{l}$ counts $)$, and $0.5 \mathrm{ml}$ for immunofluorescence studies. Samples were again taken from both does at $6 \mathrm{~h}$ after the mating or hCG. At $30 \mathrm{~h}$, i.e. about $18 \mathrm{~h}$ after ovulation, both does were killed and the oviducts were flushed. Eggs in the flushings were examined for cleavage, indicative of fertilization, by Nomarski interference microscopy.

\section{Control inseminations for sperm transfers}

Oestrous does of proven fertility were injected with 50 i.u. hCG. After $2 \mathrm{~h}$ each was anaesthetized with halothane/oxygen and at laparotomy $0.5 \mathrm{ml}$ of a suspension of washed ejaculated spermatozoa was injected into each uterine horn; samples of the suspension were diluted for counting. At $30 \mathrm{~h}$ after injection, oviduct flushings were examined for cleaving eggs.

\section{Results}

\section{Sperm recoveries}

When ejaculated spermatozoa were examined by immunofluorescence methods, the acrosomes of $>95 \%$ stained strongly for IgG after serum treatment, but if the serum step was omitted, little or no staining was observed.

There was no IgG reaction, before or after serum treatment, for spermatozoa recovered from the uterus up to $3 \mathrm{~h}$ after mating (Table 1). The spermatozoa recovered between 4 and $10 \mathrm{~h} \mathrm{p.c.}$ stained strongly even without serum treatment, and there was little change in the proportion staining or the apparent staining intensity after serum treatment. By $14 \mathrm{~h} \mathrm{p.c.,} \mathrm{the} \mathrm{proportion} \mathrm{of}$ spermatozoa staining was reduced. When oviductal spermatozoa were examined, $<60 \%$ and usually $<40 \%$ stained for $\operatorname{lgG}$, irrespective of serum treatment.

Table 1. Numbers and IgG-binding characteristics of spermatozoa recovered from the reproductive tract of female rabbits

\begin{tabular}{cccccccc}
\hline & \multicolumn{3}{c}{ Uterine spermatozoa } & & \multicolumn{3}{c}{ Oviductal spermatozoa } \\
\cline { 2 - 3 } $\begin{array}{c}\text { Time after } \\
\text { mating (h) }\end{array}$ & No. ${ }^{*} \times 10^{6}$ & $\begin{array}{c}\text { Before } \\
\text { serum }\end{array}$ & $\begin{array}{c}\text { After } \\
\text { serum }\end{array}$ & & No.* & $\begin{array}{c}\text { Before } \\
\text { serum }\end{array}$ & $\begin{array}{c}\text { After } \\
\text { serum }\end{array}$ \\
\hline 0.1 & 0 & NP & NP & 0 & NP & NP \\
0.5 & 0 & NP & NP & 0 & NP & NP \\
1.0 & $0.01 \pm 0.001$ & - & - & & 0 & NP & NP \\
2.0 & $0.093 \pm 0.003$ & - & - & $33 \pm 17$ & - & NP \\
3.0 & $0.19 \pm 0.01$ & - & - & $120 \pm 60$ & - & - \\
4.0 & $0.24 \pm 0.03$ & +++++ & +++++ & $213 \pm 22$ & & - & - \\
6.0 & $1.58 \pm 0.05$ & +++++ & +++++ & 10 & NP & ++ \\
8.0 & $0.40 \pm 0.01$ & +++++ & +++++ & $67 \pm 17$ & NP & + \\
10.0 & $1.33 \pm 0.03$ & +++ & +++++ & $450 \pm 75$ & + & + \\
14.0 & $1.53 \pm 0.03$ & + & ++ & $50 \pm 28$ & +++ & ++ \\
14.0 & $0.34 \pm 0.06$ & ++ & ++ & $13 \pm 7$ & ++ & + \\
\hline
\end{tabular}

* Values are mean \pm s.e.m. of 3 counts from each sample ( 1 doe each time).

NP, not present; - , unstained;,$+ 20 \%$ stained;,$++ 20-40 \%$ stained;,$+++ 40-60 \%$ stained;,$++++ 60-80 \%$ stained;,$+++++>80 \%$ stained.

\section{Sperm transfers}

More than $90 \%$ of the recovered eggs from the donor does were found to be cleaving normally. Table 2 shows the numbers of cleaving eggs recovered from the recipient does, and the numbers of spermatozoa associated with these fertilizations. The spermatozoa/fertilization ratio 
Table 2. Sperm numbers, spermatozoa/fertilization and IgG-binding characteristics ( - to +++++$)$ of spermatozoa recovered from the uterus of one doe (the donor, A) and transferred to another (recipient, B)

\begin{tabular}{|c|c|c|c|c|c|c|c|}
\hline \multirow[b]{3}{*}{ Exp. } & \multirow{2}{*}{\multicolumn{2}{|c|}{$\begin{array}{l}\text { Spermatozoa at } 2 \mathrm{~h} p . c . \\
\text { transferred to Doe B }\end{array}$}} & \multicolumn{3}{|c|}{ Spermatozoa at $6 \mathrm{~h} p . c}$. & \multirow{2}{*}{\multicolumn{2}{|c|}{ Eggs recovered from Doe B at 30}} \\
\hline & & & \multirow{2}{*}{$\begin{array}{c}\text { Doe } A \\
\text { IgG binding }\end{array}$} & \multicolumn{2}{|c|}{ Doe B } & & \\
\hline & No.* & IgG binding & & No. & IgG binding & $\begin{array}{l}\text { Proportion } \\
\text { fertilized }\end{array}$ & $\begin{array}{l}\text { Spermatozoa/ } \\
\text { egg fertilized }\end{array}$ \\
\hline 1 & $258 \pm 81$ & - & ++++ & NP & NP & $3 / 10$ & $86 \pm 27$ \\
\hline 2 & $2310 \pm 267$ & - & +++++ & $644 \pm 386$ & $? \dagger$ & $11 / 15$ & $151 \pm 59$ \\
\hline 3 & $2280 \pm 250$ & - & +++++ & $700 \pm 126$ & - & $11 / 14$ & $144 \pm 30$ \\
\hline
\end{tabular}

* Values are mean \pm s.e.m. for 3 counts of each sample.

$\dagger$ No usable spermatozoa were found.

was calculated as: (spermatozoa inseminated at $2 \mathrm{~h}-$ spermatozoa removed at $6 \mathrm{~h}$ ) $/ \mathrm{no}$. of eggs fertilized.

Spermatozoa were recovered from 2 of the recipients at $6 \mathrm{~h}$ p.c. and the staining reaction of these spermatozoa resembled that of the $2 \mathrm{~h}$ donor sample in being acrosome-negative, unlike the $6 \mathrm{~h}$ donor sample which had stained acrosomes. The transferred spermatozoa had therefore remained negatively-stained in the recipient, although the population from which they had come became positive.

\section{Control inseminations}

The results, expressed as spermatozoa/fertilization, are shown in Table 3.

Table 3. Sperm numbers and spermatozoa/fertilization of control ejaculate spermatozoa

\begin{tabular}{cccl}
\hline Exp. & $\begin{array}{c}\text { No.* spermatozoa } \\
\text { inseminated }\end{array}$ & $\begin{array}{c}\text { Proportion of eggs } \\
\text { fertilized }\end{array}$ & $\begin{array}{c}\text { Spermatozoa/ } \\
\text { egg fertilized }\end{array}$ \\
\hline 1 & $3.8 \pm 0.4 \times 10^{6}$ & $12 / 12$ & $3.2 \times 10^{5 \dagger}$ \\
2 & $3.9 \pm 0.4 \times 10^{5}$ & $10 / 14$ & $3.9 \pm 0.4 \times 10^{4}$ \\
& $7.4 \pm 0.5 \times 10^{6}$ & $15 / 15$ & $4.9 \times 10^{5 \dagger}$ \\
& $6.8 \pm 0.8 \times 10^{5}$ & $8 / 15$ & $8.5 \pm 0.6 \times 10^{4}$ \\
\hline
\end{tabular}

* Values are mean \pm s.e.m. for 3 counts of each sample.

$\dagger$ These are overestimates because all the eggs were fertilized.

\section{Discussion}

The immunofluorescence results clearly show that the proportion of spermatozoa capable of binding IgG from normal serum changes between ejaculation and fertilization. Most spermatozoa in the ejaculate are capable of binding IgG, but most of those in the uterus at $<3 \mathrm{~h}$ p.c. and in the oviducts at all times will not bind $\operatorname{IgG}$ from serum, and are not coated with $\operatorname{IgG}$ in the tract. Coated spermatozoa are found in the uterus after $3 \mathrm{~h} \mathrm{p.c.} \mathrm{and} \mathrm{in} \mathrm{the} \mathrm{oviduct} \mathrm{after} 10 \mathrm{~h}$.

These results are in agreement with those of Cohen \& Werrett (1975), who tested only oviductal spermatozoa and those recovered from the uterus at least 6 h p.c. Cohen \& Werrett (1975) suggested that their results could be interpreted in terms of selection of a few 'non-antigenic' spermatozoa from the ejaculate to reach the site of fertilization, with the majority being 'antigenic' and selectively removed from the female tract by antibody-coating and 
phagocytosis. The results of the present immunofluorescence experiments support this suggestion, especially when considered in connection with total sperm number in each population, and point to an additional selection procedure for non-antigenic spermatozoa at the cervix, or a change in the antigenicity of the spermatozoa during passage through the cervix. The first spermatozoa through the rabbit cervix are different from those forming the majority of the ejaculate, and from those found in the uterus a few hours later, in that they do not become coated or coatable with IgG from normal serum. Spermatozoa from the donor uterus after a few more hours are coated with IgG, but those non-staining spermatozoa (of similar age in relation to ejaculation) transferred to a recipient and sampled at $6 \mathrm{~h}$ had not coated. These spermatozoa also seem to be highly fertile in comparison with spermatozoa inseminated similarly as controls. The ratio between the number of spermatozoa inseminated and the number of fertilizations achieved agrees closely with the number of similarly non-coated spermatozoa per offspring in the study of Cohen \& MacNaughton (1974), in which spermatozoa were recovered from the oviducts and re-inseminated mixed with ejaculated or uterine spermatozoa of different genotype. We therefore agree with Overstreet et al. (1978) that the rabbit cervix may not be a passive sperm reservoir like that in ruminants (Mattner, 1966).

The coating of ejaculated spermatozoa with IgG from serum after acetone fixation has only dubious equivalence to the natural coating of spermatozoa found in the uterus. However, the finding of spermatozoa which have not been coated in the female and which are not coatable, even after acetone fixation and serum washing, plus the demonstrated high fertility of such populations, indicate correspondence between the sperm population that can be distinguished 'antigenically' and that which has a high potential to fertilize (but see Johnson \& Hunter, 1972).

However, there is no reason to suppose that these populations exist in the ejaculate and are discriminated in the female tract. Although the search for two distinct populations began because of an hypothesis supposing there to be only a small proportion of spermatozoa normally permitted to fertilize from any ejaculate (Cohen, 1973, 1975), other explanations of the present results are possible. A small number of spermatozoa may be retained in the tract for eventual fertilization, their number being below that of a real antigenic stimulus (Johnson, 1973), whilst all other spermatozoa are coated non-specifically with IgG (Cohen, 1978; Allen \& Bourne, 1978) and removed with minimal stimulation of the female's immune system, which could otherwise result in later sterility.

We thank the M.R.C. for support to K.R.T. through a Research Training Award, and Mrs J. M. Dawson for technical assistance. This study was supported in part by a W.H.O. grant (H9/181/229) to J.C.

\section{References}

Allen, G.J. \& Bourne, F.J. (1978) Interaction of immunoglobulin fragments with the mammalian sperm acrosome. J. exp. Zool. 203, 271-276.

Bedford, J.M. (1969) Morphological aspects of capacitation. In Mechanisms involved in Conception, pp. 36-50. Pergamon, Oxford.

Braden, A.W.H. (1953) Distribution of sperm in the genital tract of the female rabbit after coitus. Aust. J. Biol. Sci. 6, 693-705.

Casarett, G.W. (1953) A one-solution stain for spermatozoa. Stain Technol. 28, 125-127.

Chang, M.C. (1947) The effects of serum on spermatozoa. J. gen. Physiol. 30, 321-335.

Cohen, J. (1971) The comparative physiology of gamete populations. Adv . comp. Physiol. Biochem. 4, 268380.
Cohen, J. (1973) Crossovers, sperm redundancy and their close association. Heredity 31, 408-413.

Cohen, J. (1975) Gamete redundancy-wastage or selection? In Gamete Competition in Plants and Animals, pp. 99-112. Ed. D. L. Mulcahy. Elsevier, Amsterdam.

Cohen, J. (1978) Non-specific $(F c)$ but selective attachment of antibody to sperms. Proc. 3rd Int. Symp. Immunology of Reproduction, pp. 234-238. Ed. K. Bratanov. Bulgarian Acad. Sci. Press, Sofia.

Cohen, J. \& MacNaughton, D.C. (1974) Spermatozoa: the probable selection of a small population by the genital tract of the female rabbit. J. Reprod. Fert. 39, 297-310.

Cohen, J. \& Werrett, D.J. (1975) Antibodies and sperm survival in the female tract of the mouse and rabbit. J. Reprod. Fert. 42, 301-310.

Downloaded from Bioscientifica.com at $04 / 25 / 2023$ 11:29:17PM via free access 
Edwards, R.G. (1969) Transmission of antibodies across membranes of the reproductive tract. In Immunology and Reproduction, pp. 28-48. Ed. R. G. Edwards. I.P.P.F.

Johnson, M.H. (1973) Physiological mechanisms for the immunological isolation of spermatozoa. $A d v$. Reprod. 6, 279-323.

Johnson, W.L. \& Hunter, A.G. (1972) Seminal antigens; their alteration in the genital tract of female rabbits and during partial in vitro capacitation with $\beta$ amylase and $\beta$-glucuronidase. Biol. Reprod. 7, $332-340$.

Mattner, P.E. (1966) Formation and retention of the spermatozoan reserve in the cervix of the ruminant. Nature, Lond. 212, 1479.

Morton, D.B. (1970) On the transport of spermatozoa in the female tract. Ph.D. thesis, University of Liverpool.

Overstreet, J.W. \& Cooper, G.W. (1978) Sperm transport in the reproductive tract of the female rabbit. I.
The rapid transport phase of transport. Biol. Reprod. 19, 101-114.

Overstreet, G.W. \& Katz, D.F. (1977) Sperm transport and selection in the female tract. In Development in Mammals, Vol. 2, pp. 31-66. Ed. M. H. Johnson. Elsevier/North-Holland, Amsterdam.

Overstreet, G.W., Cooper, G.W. \& Katz, D.F. (1978) Sperm transport in the reproductive tract of the female rabbit. II. The sustained phase of transport. Biol. Reprod. 19, 115-132.

Padma, M.C. (1972) Presence of a sperm-agglutinating factor in the normal serum of rabbits against homologous spermatozoa. J. Reprod. Fert. 31, $119-122$.

Symons, D.B.A. (1967) Reaction of spermatozoa with uterine and serum globulin determined by immunofluorescence. J. Reprod. Fert. 14, 163-165.

Tyler, K.R. (1977) Histological changes in the cervix of the rabbit after coitus. J. Reprod. Fert. 49, 341-345.

Received 5 February 1980 